\title{
COLLATERAL FLOW PREVENTS UNINTENTIONAL MYOCARDIAL ISCHEMIA DURING ANTEGRADE CARDIOPLEGIA IN PATIENTS UNDERGOING CORONARY ARTERY BYPASS GRAFTING
}

Quintilio Caretta, $\mathrm{MD}^{\mathrm{a}}$

Paolo Voci, MD, $\mathrm{PhD}^{\mathrm{b}}$

Maria Cristina Acconcia, $\mathrm{MD}^{\mathrm{b}}$

Flavia Chiarotti, BS ${ }^{\mathrm{c}}$
Objective: We evaluated, in the prevention of perioperative unintentional myocardial ischemia, the role of coronary collateral flow in patients with left anterior descending coronary artery stenosis or occlusion who underwent elective coronary artery bypass grafting. Methods: Coronary lesions and collaterals were assessed by coronary angiography in 21 patients. Anteroseptal myocardial viability was evaluated by dobutamine echocardiography. Antegrade perfusion of cardioplegic solution was assessed by myocardial contrast echocardiography. Time-intensity curves were generated from the anteroseptal region. Twelve parameters were measured and averaged in the following four groups of patients: those with stenosis of the left anterior descending artery and poor collaterals; those with stenosis of the left anterior descending artery and good collaterals; those with occlusion of the left anterior descending artery and good collaterals; and those with occlusion of the left anterior descending artery and poor collaterals. Results: Time-intensity curves were significantly different in patients with stenosis versus occlusion of the left anterior descending artery $(p<0.005)$; multiple comparisons with Bonferroni's correction showed that this difference was mainly a result of the impact of collateral circulation $(p<0.01)$. However, the role of collaterals was nonsignificant within the groups with stenosis and occlusion of the left anterior descending artery. Patients with occlusion of the left anterior descending artery and good collaterals had perfusion parameters similar to those of patients with stenosis of the left anterior descending artery ( $p=$ not significant), except for the ascending slope and time to peak values $(p<0.05$ and $p<0.01$, respectively), which reflected a higher flow resistance in the collateral circulation. Regional systolic function after coronary artery bypass grafting was depressed in patients with poor collaterals and poor perfusion of cardioplegic solution, as compared with findings in other subgroups. Conclusions: Incomplete myocardial protection may impair the early recovery of function after coronary artery bypass grafting. (J Thorac Cardiovasc Surg 1997;113:585-93)
From the University of Florence, ${ }^{\text {a }}$ Florence; the Department of Cardiac Surgery, "La Sapienza" University of Rome, ${ }^{\text {b Rome; }}$ and the Istituto Superiore di Sanità, Ministero della Sanità, Rome, Italy.

Supported in part by M.U.R.S.T. grant 05150108-C0533 from the University of Rome "La Sapienza" and by Consiglio Nazionale delle Ricerche grant 95.02471.CT04.

Received for publication Jan. 18, 1996; revisions requested March 18, 1996; revisions received August 5, 1996; accepted for publication August 8, 1996.

Address for reprints: Quintilio Caretta, MD, Via G. Giolitti 198, 00185 Rome, Italy.

Copyright (C) 1997 by Mosby-Year Book, Inc.

$0022-5223 / 97 \$ 5.00+0 \quad \mathbf{1 2 / 1 / 7 7 1 8 5}$
The role of coronary collateral circulation in preserving regional myocardial perfusion has been demonstrated by coronary angiography, ${ }^{1,2}$ by nuclear methods, ${ }^{3}$ and, more recently, by myocardial contrast echocardiography (MCE). ${ }^{4-8}$ Coronary angiography detects vessels of greater than $100 \mu \mathrm{m}$ in diameter and might underestimate collateral flow in patients with poor collateral circulation. ${ }^{7}$ Preoperative perfusion imaging techniques may not predict the intraoperative perfusion pattern, because during delivery of cardioplegic solution (1) the flow pattern may be different from that of the beating heart, (2) there is maximal vasodilation of the microcircula- 
Table I. Clinical and coronary angiographic findings

\begin{tabular}{|c|c|c|c|c|}
\hline & \multicolumn{2}{|c|}{ LAD stenosis } & \multicolumn{2}{|c|}{$L A D$ occlusion } \\
\hline & $\begin{array}{c}\text { Good } \\
\text { collaterals }\end{array}$ & $\begin{array}{c}\text { Poor } \\
\text { collaterals }\end{array}$ & $\begin{array}{c}\text { Good } \\
\text { collaterals }\end{array}$ & $\begin{array}{c}\text { Poor } \\
\text { collaterals }\end{array}$ \\
\hline No. of patients & 4 & 8 & 5 & 4 \\
\hline $\begin{array}{l}\text { Age in years } \\
\quad(\text { mean } \pm \mathrm{SD})\end{array}$ & $54.8 \pm 4.3$ & $58.9 \pm 8.3$ & $55.8 \pm 7.5$ & $60.5 \pm 8.7$ \\
\hline \multicolumn{5}{|l|}{ Sex } \\
\hline Male & 4 & 7 & 5 & 3 \\
\hline Female & 0 & 1 & 0 & 1 \\
\hline \multicolumn{5}{|l|}{ Previous anterior MI } \\
\hline Yes & 1 & 1 & 1 & 1 \\
\hline No & 3 & 7 & 4 & 3 \\
\hline \multicolumn{5}{|l|}{ Hypertension } \\
\hline Yes & 1 & 3 & 3 & 4 \\
\hline No & 3 & 5 & 2 & 0 \\
\hline \multicolumn{5}{|l|}{ Diabetes } \\
\hline Yes & 1 & 2 & 1 & 1 \\
\hline No & 3 & 6 & 4 & 3 \\
\hline \multicolumn{5}{|l|}{ Regional LV function } \\
\hline Normal $(\geq 50 \%)$ & 3 & 5 & 3 & 0 \\
\hline $\begin{array}{l}\text { Impaired } \\
\quad(49 \%-20 \%)\end{array}$ & 0 & 2 & 1 & 3 \\
\hline $\begin{array}{l}\text { Severely impaired } \\
(<20 \%)\end{array}$ & 1 & 1 & 1 & 1 \\
\hline
\end{tabular}

$S D$, Standard deviation; $M I$, myocardial infarction; $L V$, left ventricular.

tion, including collateral vessels, and (3) perfusateinduced endothelial damage may occur., 10

MCE may provide information on myocardial perfusion in the beating or arrested heart ${ }^{4,8,11-17}$ and may be used to study distribution of cardioplegic solution during coronary artery bypass grafting $(\mathrm{CABG}) .{ }^{8,12,14,15}$ In patients with coronary occlusion, nonhomogeneous distribution of cardioplegic solution delivered in an antegrade manner may cause "unintentional myocardial ischemia," which may lead to myocardial stunning or necrosis. ${ }^{18-20}$ In this clinical setting, the role of collateral circulation is critical, and the identification of inadequate myocardial perfusion may help the surgeon plan combined antegrade/retrograde cardioplegia procedures. ${ }^{4,8,20}$

The aim of the present study was to evaluate by intraoperative MCE the protective role of coronary collateral flow on preserving myocardial perfusion and function in patients with symptomatic chronic coronary artery disease and proximal left anterior descending artery (LAD) stenosis or occlusion who underwent elective coronary operation.

\section{Methods}

Patient selection. Twenty-one patients undergoing elective CABG because of symptomatic chronic coronary
Table II. Parameters of the videointensity curves

\begin{tabular}{lcc}
\hline \multicolumn{1}{c}{ Parameters } & $\begin{array}{c}\text { LAD stenosis } \\
\left(n^{*}=12\right)\end{array}$ & $\begin{array}{c}\text { LAD occlusion } \\
(n=9)\end{array}$ \\
\hline Peak height & \multicolumn{1}{c}{ Videointensity units } \\
Area at $1 \mathrm{sec}$ & $16.2 \pm 14.5$ & $22.0 \pm 12.3$ \\
Area at $2 \mathrm{sec}$ & $54.7 \pm 22.9$ & $4.1 \pm 2.2$ \\
Area at $3 \mathrm{sec}$ & $98.1 \pm 33.5$ & $15.1 \pm 7.7$ \\
Area at $4 \mathrm{sec}$ & $136.0 \pm 40.1$ & $49.6 \pm 16.0$ \\
Area at $5 \mathrm{sec}$ & $164.4 \pm 44.5$ & $70.2 \pm 38.0$ \\
Area at $6 \mathrm{sec}$ & $185.3 \pm 50.7$ & $90.4 \pm 49.7$ \\
Area at $7 \mathrm{sec}$ & $200.9 \pm 56.5$ & $106.1 \pm 59.9$ \\
Area at peak & $64.5 \pm 25.9$ & $68.0 \pm 42.6$ \\
& \multicolumn{2}{c}{ Videointensity units/sec } \\
Ascending slope & $23.4 \pm 10.5$ & $4.4 \pm 2.6$ \\
Descending slope & $-7.7 \pm 3.4$ & $-4.3 \pm 2.8$ \\
& \multicolumn{2}{c}{ Time (sec) } \\
Time to peak & $2.3 \pm 0.6$ & $4.8 \pm 0.6$
\end{tabular}

Values are expressed as mean plus or minus standard deviation.

*Number of patients.

artery disease and proximal lesions of the LAD were enrolled in this study. Approval of the study protocol by the institution's Ethics Committee on Clinical Investigations and informed consent from each patient were obtained. Coronary artery lesions were considered significant when cross-sectional area loss was $75 \%$ or greater; arteries were considered occluded when cross-sectional area loss was $100 \%$.

Coronary collateral circulation was classified into two categories (good and poor) on the basis of the degree of opacification of the epicardial segment of the recipient artery on the coronary angiograms. ${ }^{2}$ In patients with good collateral circulation, both collaterals and epicardial arteries distal to an occlusion or stenosis were well visualized. Conversely, in patients with poor collateral circulation, the visualization of collaterals and epicardial arteries distal to an occlusion or stenosis was faint. Patients with aortic incompetence or left ventricular aneurysm were excluded from the study. Wall motion was observed in the biplanar left ventriculogram in all patients. Left anteroseptal wall motion was graded on the basis of angiographically determined regional ejection fraction into normal $(\geq 50 \%)$, impaired $(49 \%$ to $20 \%)$, and severely impaired $(<20 \%)$. Clinical and coronary angiographic findings are shown in Table I.

Anesthetic technique. Anesthesia was induced with fentanyl (30 to $35 \mu \mathrm{g} / \mathrm{kg}$ ), diazepam ( 0.25 to $0.5 \mathrm{mg} / \mathrm{kg}$ ), and succinylcholine $(1.5 \mathrm{mg} / \mathrm{kg})$ and was maintained with fentanyl, droperidol, pancuronium bromide, and a $50 \%$ $\mathrm{N}_{2} \mathrm{O}$ and oxygen mixture.

Surgical technique. CABG was done during cardiopulmonary bypass. Systemic hypothermia $\left(25^{\circ}\right.$ to $\left.28^{\circ} \mathrm{C}\right)$ was maintained throughout the procedure. A total of 79 grafts (average $3.8 \pm 1.2$ grafts per patient) were placed: 58 were of inverted saphenous vein and 21 of internal thoracic artery. The internal thoracic arteries were always grafted to the LAD. 


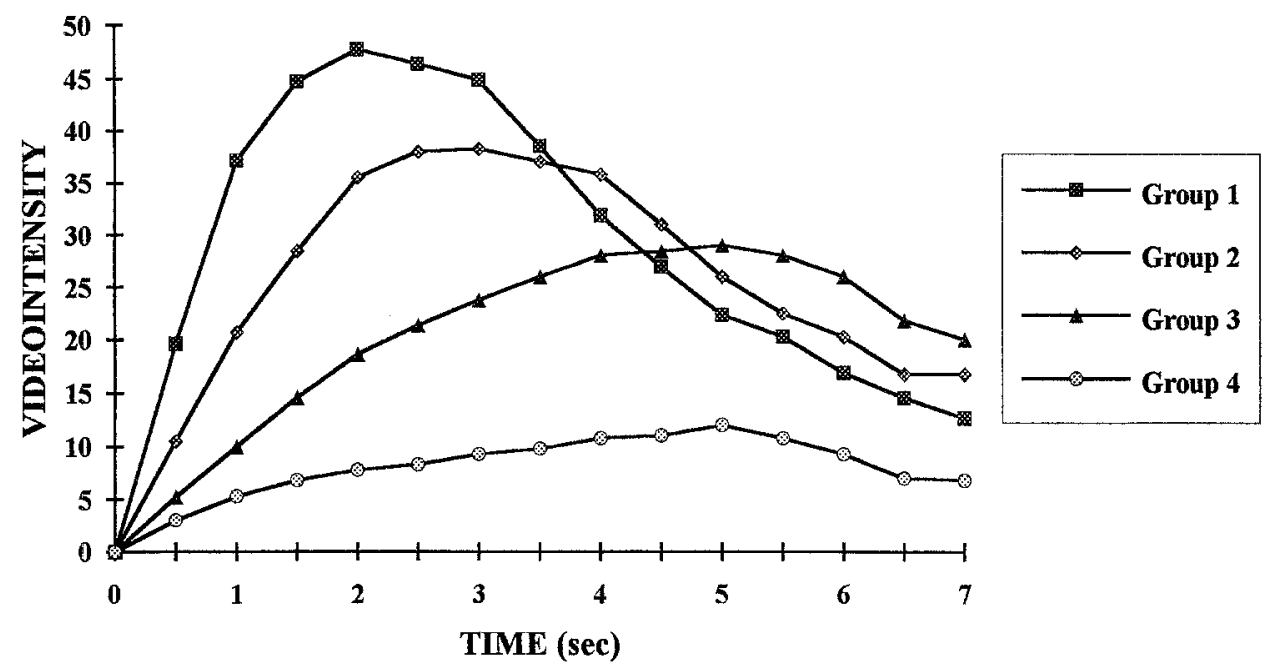

Fig. 1. Cumulative time-intensity curves from images obtained in the four subgroups of patients. Group 1 , Patients with LAD stenosis and poor collaterals; group 2, patients with LAD stenosis and good collaterals; group 3, patients with LAD occlusion and good collaterals; group 4, patients with LAD occlusion and poor collaterals.

Cardioplegia techniques. Myocardial protection was achieved by inducing topical hypothermia with iced saline slush and by administration of cold $\left(4^{\circ} \mathrm{C}\right)$ potassium crystalloid cardioplegic solution $(30 \mathrm{mEq} / \mathrm{L}$ of potassium chloride in the first dose and $15 \mathrm{mEq} / \mathrm{L}$ in all the subsequent doses). Cardioplegic solution was infused in an antegrade manner via the aortic root at a pressure of 70 to $80 \mathrm{~mm} \mathrm{Hg}$. An initial volume of cardioplegic solution $(10 \mathrm{ml} / \mathrm{kg})$ was infused over 2 minutes through the aortic root. Left ventricular venting was done through the left atrium. Administration of cardioplegic solution was repeated every 20 minutes throughout the ischemic period with a $15 \mathrm{mEq} / \mathrm{L}$ potassium concentration.

Assessment of myocardial viability. All patients underwent preoperative (transthoracic) and intraoperative (transesophageal) dobutamine echocardiographic testing at a dose of $5 \mu \mathrm{g} / \mathrm{kg}$ per minute to study myocardial viability in the anteroseptal wall. Preoperative assessment was done in the standard parasternal and apical views, and the anteroseptal wall was assigned one of the following wall motion scores: -1 , hyperkinetic; 0 , normal; 1 , hypokinetic; 2, akinetic; and 3, dyskinetic. The intraoperative assessment was done by single-plane transesophageal echocardiography, with use of a previously reported method. ${ }^{21}$ Myocardial wall thickness was measured during the same cardiac cycle at end systole (SWT) and at end diastole (DWT). ${ }^{21}$ Percent systolic wall thickening (PSWT) of the anteroseptal wall was calculated according to the formula

$$
\text { PSWT }=\frac{\text { SWT }- \text { DWT }}{\text { DWT }} \times 100
$$

Serial 12-lead electrocardiograms and cardiac enzyme measurements (creatine kinase MB) were done to exclude the occurrence of perioperative myocardial infarction.
Echocardiographic contrast agent. The echocardiographic contrast agent was prepared under sterile conditions 1 hour before the operation with use of a standardized protocol developed at the University of Rome, "La Sapienza,"22 and based on guidelines for albumin sonication developed at the University of Chicago. ${ }^{23}$

Perfusion imaging technique. Aortic incompetence, which may cause inadequate myocardial perfusion during antegrade cardioplegia, ${ }^{15}$ was ruled out before bypass by transesophageal echocardiographic color Doppler imaging.

The echocardiographic contrast agent was injected soon after hypothermic arrest through a side branch of the cardioplegia conduit. Two contrast injections of $2 \mathrm{ml}$ were scheduled for each patient during antegrade cardioplegia. The first injection was done during imaging of the aortic valve and the left ventricle to rule out unexpected aortic regurgitation during aortic crossclamping ${ }^{15}$; the second injection was done during imaging of the left ventricle in the short-axis view at the level of the papillary muscle to evaluate myocardial perfusion.

Contrast echocardiographic analysis. Contrast echocardiograms were recorded on SVHS magnetic tape and digitized off-line with use of a 151 Imaging Technology image processor connected with an IBM PS-2 80 computer and displayed on a 512 by 512 pixel screen with 256 gray level scale or intensity units per pixel. One region of interest of at least 100 pixels was drawn in the midanteroseptal wall of the left ventricular myocardium, excluding endocardial and epicardial borders. Quantitative measurements were made by continuous, automatic acquisition at a rate of 15 frames/sec, starting before contrast appearance and continuing for 7 seconds. Backgroundsubtracted time-intensity curves were generated and averaged in four patient groups: those with LAD stenosis and 
Table III. Results of univariate analysis of variance

\begin{tabular}{|c|c|c|c|c|c|}
\hline \multirow[b]{2}{*}{ Parameters } & \multirow[b]{2}{*}{$\begin{array}{l}\text { LAD stenosis } \\
(n=12)^{*}\end{array}$} & \multirow[b]{2}{*}{$\begin{array}{l}\text { LAD occlusion } \\
\quad(n=9) \dagger\end{array}$} & \multicolumn{3}{|c|}{$p$ Values } \\
\hline & & & $\begin{array}{l}\text { Main effect, } \\
\text { LAD disease }\end{array}$ & $\begin{array}{c}\text { Main effect, } \\
\text { collaterals }\end{array}$ & Interaction $\frac{\dot{t}}{+}$ \\
\hline \multicolumn{6}{|c|}{ Videointensity units } \\
\hline Peak height & & & 0.0003 & 0.5439 & 0.0157 \\
\hline Good collaterals & $40.0 \pm 7.8$ & $30.0 \pm 10.8$ & & & \\
\hline Poor collaterals & $51.3 \pm 15.9$ & $12.0 \pm 2.4$ & & & \\
\hline Area at peak & & & 0.9234 & 0.0662 & 0.0271 \\
\hline Good collaterals & $60.5 \pm 11.8$ & $93.7 \pm 41.6$ & & & \\
\hline Poor collaterals & $66.5 \pm 31.4$ & $35.9 \pm 7.0$ & & & \\
\hline Area at $1 \mathrm{sec}$ & & & 0.0018 & 0.2928 & 0.0795 \\
\hline Good collaterals & $10.4 \pm 5.8$ & $5.1 \pm 2.5$ & & & \\
\hline Poor collaterals & $19.1 \pm 9.1$ & $2.8 \pm 0.7$ & & & \\
\hline Area at $2 \mathrm{sec}$ & & & 0.0001 & 0.3630 & 0.0342 \\
\hline Good collaterals & $38.8 \pm 15.6$ & $19.6 \pm 7.8$ & & & \\
\hline Poor collaterals & $62.7 \pm 22.4$ & $9.4 \pm 1.7$ & & & \\
\hline Area at $3 \mathrm{sec}$ & & & $<0.0001$ & 0.6667 & 0.0231 \\
\hline Good collaterals & $76.2 \pm 21.4$ & $40.9 \pm 14.5$ & & & \\
\hline Poor collaterals & $109.0 \pm 34.0$ & $17.8 \pm 2.2$ & & & \\
\hline Area at $4 \mathrm{sec}$ & & & $<0.0001$ & 0.8676 & 0.0198 \\
\hline Good collaterals & $113.2 \pm 25.5$ & $66.8 \pm 23.5$ & & & \\
\hline Poor collaterals & $147.5 \pm 42.5$ & $27.7 \pm 2.5$ & & & \\
\hline Area at $5 \mathrm{sec}$ & & & $<0.0001$ & 0.4547 & 0.0208 \\
\hline Good collaterals & $144.1 \pm 29.1$ & $95.3 \pm 33.5$ & & & \\
\hline Poor collaterals & $174.5 \pm 49.0$ & $38.9 \pm 3.7$ & & & \\
\hline Area at $6 \mathrm{sec}$ & & & 0.0002 & 0.2736 & 0.0237 \\
\hline Good collaterals & $166.9 \pm 31.3$ & $123.0 \pm 43.8$ & & & \\
\hline Poor collaterals & $194.4 \pm 57.7$ & $49.6 \pm 5.8$ & & & \\
\hline Area at $7 \mathrm{sec}$ & & & 0.0007 & 0.1886 & 0.0270 \\
\hline Good collaterals & $184.6 \pm 32.2$ & $145.4 \pm 52.8$ & & & \\
\hline \multirow[t]{2}{*}{ Poor collaterals } & $209.0 \pm 65.9$ & $57.1 \pm 7.6$ & & & \\
\hline & \multicolumn{2}{|c|}{ Videointensity units/sec } & & & \\
\hline Ascending slope & & & 0.0001 & 0.3279 & 0.0445 \\
\hline Good collaterals & $16.2 \pm 5.8$ & $6.1 \pm 2.2$ & & & \\
\hline Poor collaterals & $26.9 \pm 10.8$ & $2.2 \pm 0.7$ & & & \\
\hline Descending slope & & & 0.0380 & 0.8255 & 0.0669 \\
\hline Good collaterals & $-6.1 \pm 1.7$ & $-5.7 \pm 3.3$ & & & \\
\hline \multirow[t]{2}{*}{ Poor collaterals } & $-8.5 \pm 3.9$ & $-2.7 \pm 0.5$ & & & \\
\hline & \multicolumn{2}{|c|}{ Time (sec) } & & & \\
\hline Time to peak & & & $<0.0001$ & 0.2891 & 0.3727 \\
\hline Good collaterals & $2.6 \pm 0.5$ & $4.8 \pm 0.8$ & & & \\
\hline Poor collaterals & $2.1 \pm 0.6$ & $4.8 \pm 0.5$ & & & \\
\hline
\end{tabular}

Values are expressed as mean plus or minus standard deviation.

${ }^{*}$ Four patients with good collaterals, 8 patients with poor collaterals.

$\dagger$ Five patients with good collaterals, 4 patients with poor collaterals.

¥Interaction refers to comparisons among patients with LAD disease (stenosis versus occlusion) and good or poor collaterals.

poor collaterals; those with LAD stenosis and good collaterals; those with LAD occlusion and good collaterals; and those with LAD occlusion and poor collaterals. For each curve the following parameters were calculated: time to peak, peak of the curve, area at peak, area under the curve at every 0.5 second up to 7 seconds, and slope of the regression lines fitted to the curve in two segments, ascending slope (from baseline to peak) and descending slope (from peak to the end of the curve). The ascending slope described contrast wash-in in the myocardium and the descending slope described contrast wash-out from the myocardium (see appendix).

Statistical analysis. Categorical data were presented as absolute frequency. Quantitative measurements were expressed as mean plus or minus the standard deviation. Clinical and angiographic findings were compared by analysis of variance (ANOVA) for quantitative variables and Fisher's exact probability test for categorical variables. PSWT changes in the anteroseptal wall throughout the study were analyzed by paired Student's $t$ test with 
Table IV. Probability ( $p$ ) values of the multiple comparisons with Bonferroni's correction

\begin{tabular}{|c|c|c|c|c|}
\hline \multirow[b]{2}{*}{ Parameters } & \multicolumn{2}{|c|}{ Good vs poor collaterals } & \multicolumn{2}{|c|}{ LAD stenosis vs occlusion } \\
\hline & $\begin{array}{l}\text { LAD stenosis } \\
\left(n^{*}=12\right)\end{array}$ & $\begin{array}{l}\text { LAD occlusion } \\
\quad(n=9)\end{array}$ & $\begin{array}{c}\text { Good collaterals } \\
(n=9)\end{array}$ & $\begin{array}{c}\text { Poor collaterals } \\
\quad(n=12)\end{array}$ \\
\hline Peak height & NS & $<0.08$ & NS & $<0.003$ \\
\hline Area at peak & NS & NS & NS & NS \\
\hline Area at $1 \mathrm{sec}$ & NS & NS & NS & $<0.006$ \\
\hline Area at $2 \mathrm{sec}$ & NS & NS & NS & $<0.002$ \\
\hline Area at $3 \mathrm{sec}$ & NS & $<0.10$ & $<0.09$ & $<0.001$ \\
\hline Area at $4 \mathrm{sec}$ & NS & $<0.06$ & NS & $<0.001$ \\
\hline Area at $5 \mathrm{sec}$ & NS & $<0.06$ & NS & $<0.001$ \\
\hline Area at $6 \mathrm{sec}$ & NS & $<0.06$ & NS & $<0.001$ \\
\hline Area at $7 \mathrm{sec}$ & NS & $<0.08$ & NS & $<0.002$ \\
\hline Ascending slope & NS & $<0.06$ & $<0.04$ & $<0.002$ \\
\hline Descending slope & NS & NS & NS & $<0.02$ \\
\hline Time to peak & NS & NS & $<0.01$ & $<0.001$ \\
\hline
\end{tabular}

$p$ Values reported are expressed according to the following approximation, e.g: $p<0.08 \Rightarrow 0.07<p<0.08$; NS, Not significant.

*Number of patients.

Bonferroni's correction. PSWT paired values were compared at two steps: baseline versus dobutamine infusion and baseline versus after surgical revascularization. The parameters obtained from the time-intensity curves were analyzed by univariate ANOVA with LAD stenosis versus occlusion and good versus poor collateral circulation as between-subject factors. In particular, the ANOVA model included main effects of LAD disease and collateral circulation and their interaction. Multiple comparisons were done by applying the appropriate $t$ test with Bonferroni's correction. A $p$ value of $\leq 0.05$ was considered statistically significant; $p$ values between 0.10 and 0.05 are also reported in the tables and text. Statistical analysis was done with BMDP/Dynamic software, release 7.0.24

\section{Results}

Clinical variables among the four patient groups were not statistically different (Table I).

Preoperative assessment of myocardial viability. Preoperative dobutamine transthoracic echocardiography showed viable myocardium in the anteroseptal wall in all patients (wall motion score index $0.7 \pm 0.8$ to $-0.4 \pm 0.7 ; p<0.0001$ ), with clear indication for revascularization in all patients, including those with LAD occlusion and poor collaterals.

Intraoperative perfusion imaging. Cumulative time-intensity curves generated from the opacification of the anteroseptal myocardium are shown in Fig. 1. Variable values of the curves are presented in Tables II and III. Univariate ANOVA showed that patients with LAD occlusion had a significant delay in time to peak, a significant lower peak height of the curve, and a lower area under the curve than patients with LAD stenosis (Table III). The contrast wash-in, measured by the ascending slope of the curve, and the contrast wash-out, measured by the descending slope of the curve, were significantly lower in patients with LAD occlusion versus respective values in those with LAD stenosis alone. A significant interaction between LAD disease and collateral circulation was found with respect to all parameters, except for time to peak, area at 1 second, and the descending slope (Table III). Multiple comparison tests showed that the gap between LAD stenosis versus occlusion was mainly a result of the impact of poor collaterals for all the variables, but not the area at peak (Table IV). Conversely, in the presence of well-developed collateral circulation, a significant difference only persisted between patients with $\mathrm{LAD}$ stenosis and patients with $\mathrm{LAD}$ occlusion with respect to time to peak and ascending slope of the curve (Table IV). Furthermore, within the LAD stenosis and LAD occlusion groups, perfusion parameters were not affected by the presence of good or poor collaterals (Table IV, Fig. 1). The lack of any significant difference in the area at peak among the patient groups was probably related to the different times to peak in each group (Fig. 1, Tables III and IV).

Figs. 2 and 3 are color-coded echocardiograms obtained during administration of contrast-enhanced cardioplegic solution in two patients with LAD occlusion. Fig. 2 depicts findings in a patient without collateral circulation in whom a clear-cut perfusion defect was detected in the anteroseptal wall. Myocardial perfusion is best appreciated in the background-subtracted image (Fig. 2, lower panel), which shows the net effect of microbubble diffusion 

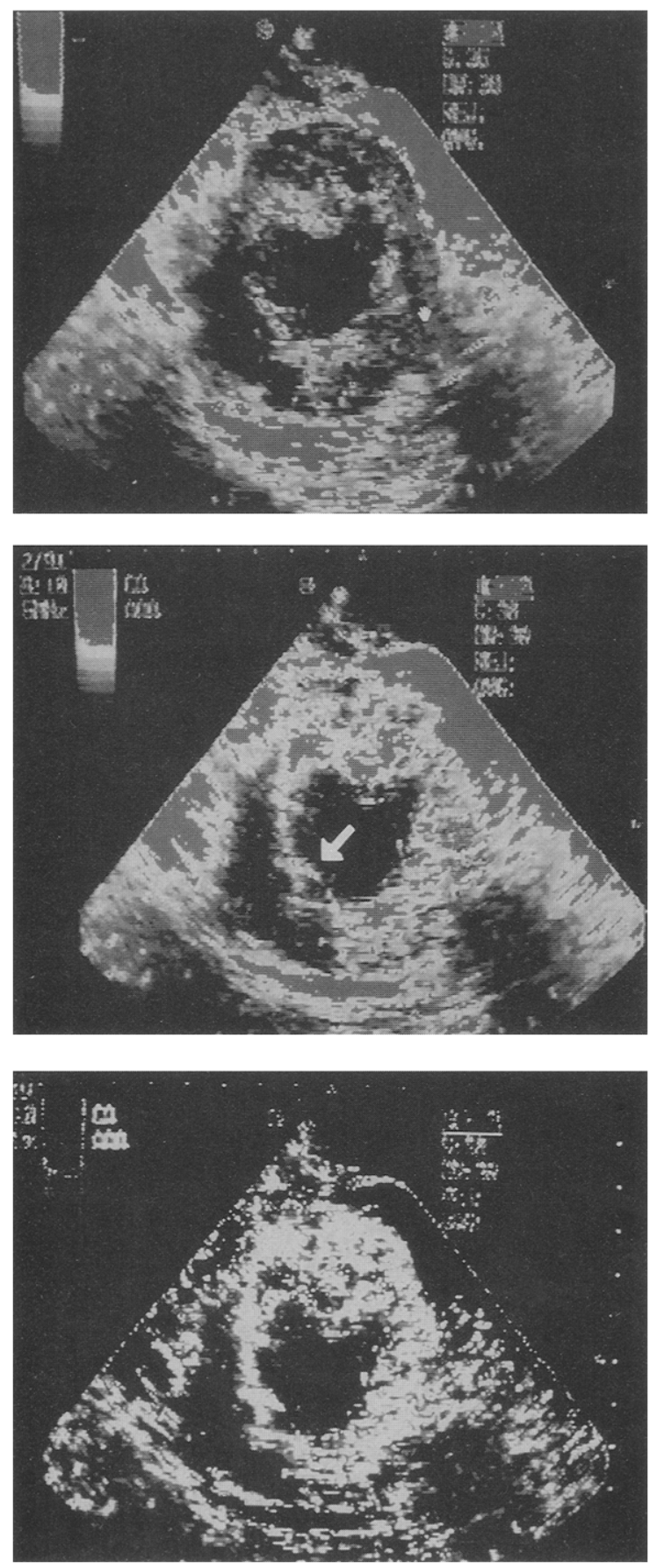

Fig. 2. Intraoperative transesophageal echocardiography during antegrade administration of cardioplegic solution showing color-coded left ventricular short-axis view before (upper panel) and during (middle and lower panels) contrast injection in a patient with occluded LAD and poor collateral circulation. The arrow shows the perfusion defect in the anteroseptal wall. The lower panel is a digitally subtracted image from those in the middle and upper panels, showing residual perfusion in the subendocardium.
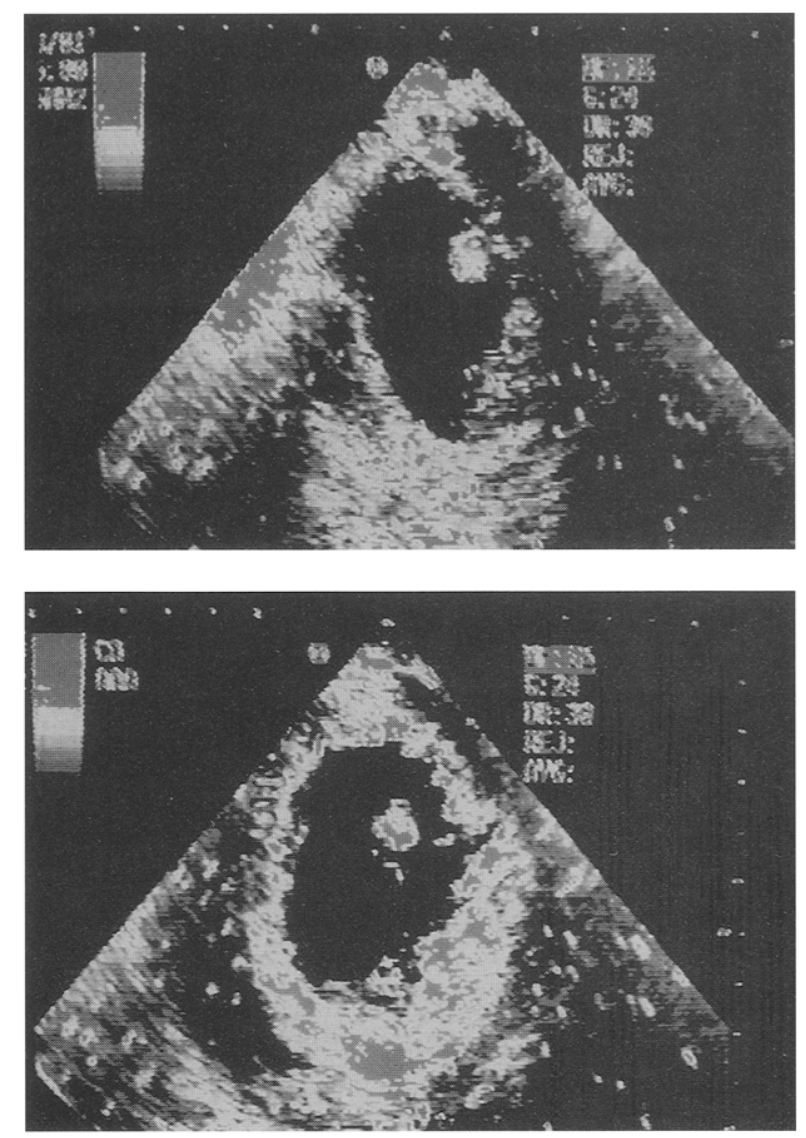

Fig. 3. Intraoperative transesophageal echocardiography during antegrade administration of cardioplegic solution showing color-coded left ventricular short-axis view before (upper panel) and after (lower panel) contrast injection in a patient with occluded LAD and good collateral circulation. The lower panel shows good perfusion of the anteroseptal wall.

through the myocardium with subendocardial pooling of the agent in the anteroseptal wall. Fig. 3 depicts findings in a patient with good collateral circulation in whom the anteroseptal wall was well perfused.

Intraoperative assessment of myocardial viability. Intraoperative dobutamine echocardiography testing confirmed myocardial viability in the anteroseptal wall, with PSWT values increasing from $12.6 \% \pm 8.2 \%$ at baseline to $25.9 \% \pm 13.9 \%$ during dobutamine infusion at $5 \mu \mathrm{g} / \mathrm{kg}$ per minute $(p<$ $0.0001)$ in all patients and from $9.0 \% \pm 8.5 \%$ at baseline to $25.3 \% \pm 12.7 \%$ during dobutamine infusion $(p<0.05)$ in patients with LAD occlusion and poor collaterals (Table V, group 4). In this subgroup, antegrade distribution of cardioplegic so- 
Table V. PSWT of the anteroseptal region at baseline, during dobutamine infusion, and after CABG in the four subgroups of patients with LAD disease

\begin{tabular}{cccccccc}
\hline & & \multicolumn{3}{c}{ PSWT (\%) } & & \multicolumn{2}{c}{$p$ Values } \\
\cline { 3 - 5 } Group & No. of patients & Baseline & $\begin{array}{c}\text { Dobutamine } \\
\text { infusion }\end{array}$ & $\begin{array}{c}\text { After } \\
\text { CABG }\end{array}$ & & $\begin{array}{c}\text { Baseline vs } \\
\text { dobutamine }\end{array}$ & $\begin{array}{c}\text { Baseline vs after } \\
\text { CABG }\end{array}$ \\
\hline Group 1 & 8 & $13.4 \pm 9.6$ & $28.8 \pm 18.5$ & $32.4 \pm 14.1$ & & $<0.02$ & $<0.002$ \\
Group 2 & 4 & $10.3 \pm 6.3$ & $20.3 \pm 9.3$ & $21.8 \pm 7.4$ & & $<0.05$ & $<0.02$ \\
Group 3 & 5 & $16.2 \pm 7.1$ & $26.4 \pm 11.7$ & $38.6 \pm 17.5$ & & $<0.05$ & $<0.03$ \\
Group 4 & 4 & $9.0 \pm 8.5$ & $25.3 \pm 12.7$ & $16.3 \pm 7.4$ & & $<0.05$ & $<0.08$ \\
All patients & 21 & $12.6 \pm 8.2$ & $25.9 \pm 13.9$ & $28.8 \pm 14.8$ & & $<0.0001$ & $<0.0001$ \\
\hline
\end{tabular}

Values are expressed as mean plus or minus standard deviation. Group 1, LAD stenosis and poor collaterals; group 2, LAD stenosis and good collaterals group 3, LAD occlusion and good collaterals; group 4, LAD occlusion and poor collaterals. p Values reported are expressed according to the following approximation, e.g: $p<0.02 \stackrel{\Rightarrow}{\Rightarrow} 0.01<p<0.02$.

lution to the anteroseptal wall was poor, but digitalsubtracted images showed a clear subendocardial perfusion (Fig. 2, lower panel). Postoperative systolic function after weaning from cardiopulmonary bypass was lower in this subgroup (PSWT from 9.0\% $\pm 8.5 \%$ to $16.3 \% \pm 7.4 \% ; p<0.08$ ) when compared with that in the other subgroups with good collaterals or no LAD occlusion (Table V).

No patients had new $Q$ waves and pathologic release of creatine kinase $\mathrm{MB}$ after the operation.

\section{Discussion}

The goal of the cardioprotective approach during cardiac operations is to avoid myocardial stunning or necrosis; however, the ideal approach has not yet been established. Current data suggest that antegrade cardioplegia, in the presence of severe coronary artery stenosis or occlusion, may result in "unintentional myocardial ischemia" because of nonhomogeneous myocardial perfusion and cooling. ${ }^{18-20}$ Retrograde cardioplegia can be used as an alternative, but more critical information on the pathophysiologic processes of retrograde perfusion is needed, ${ }^{20,25}$ and the right atrial approach cannot be used in patients with either atrial septal defect or patent foramen ovale. ${ }^{15}$

Myocardial flow in the arrested heart differs from that in the beating heart and may not be anticipated by preoperative perfusion imaging techniques. For this reason MCE may play a central role in intraoperative myocardial protection protocols because it allows detection of myocardial regions susceptible to inadequate perfusion. ${ }^{4,6,8,11-15,17}$ Quantitative MCE can be successfully used to identify myocardial regions that are receiving the least amount of cardioplegic solution, and several parameters derived from time-intensity curves may be used to study regional myocardial flow. ${ }^{4,13,14}$ This method allows
(1) detection of myocardial regions that escape the ischemic insult ${ }^{4}$; (2) improvement of the identification of collateral flow in comparison with coronary angiography $y^{5,6}$; and (3) evaluation of transmural blood flow distribution. ${ }^{4}$

The question related to the adequacy of collateral flow in the prevention of ischemia of the collateralized myocardium is still unanswered. ${ }^{4,5,8}$ Coronary collaterals differ in terms of anatomy and flow pattern from the normal arterial vessels because they are characterized by marked endothelial cell proliferation and subintimal hyperplasia. ${ }^{26,27}$ On the other hand, it has been demonstrated by temperature probes that good collateral circulation in patients with chronic, stable angina provides homogeneous myocardial cooling that is independent of the route chosen for infusion of cardioplegic solution. ${ }^{4,8}$ However, this monitoring technique may be inadequate $^{28}$ and is useless when normothermic cardioplegia is used. In addition, data on the protective role of poor collaterals are lacking.

The results of the present study confirm the role of intraoperative $\mathrm{MCE}$ in the assessment of regional myocardial flow and the importance of collateral flow in protecting areas fed by an obstructed major coronary vessel. Parameters related to contrast wash-in (time to peak and ascending slope of the curve) and contrast wash-out (descending slope of the curve) were significantly different between patients with LAD stenosis and patients with LAD occlusion (Tables III and IV). This finding confirms that during cardioplegia-induced maximal vasodilation collateral circulation represents a resistance to flow that is functionally comparable to a significant stenosis of a native coronary artery. ${ }^{9,10,29}$ Blood volume parameters (area under the time-intensity curve and peak of the curve) were not statistically different in the subgroups with LAD stenosis and occlusion when good collaterals 
were present (Table IV, good collaterals column). In patients with LAD occlusion the whole area under the curve was not significantly affected by the presence of collateral circulation as shown by preoperative coronary arteriography (Fig. 1; Table IV, LAD occlusion column). However, when poor collaterals were considered as a grouping factor, perfusion parameters were significantly lower in patients with LAD occlusion in the absence of postoperative electrocardiographic and enzymatic evidence of myocardial infarction. In accordance with the guidelines of the American Society of Anesthesiologists, ${ }^{30}$ perioperative echocardiography may allow detection of poorly protected myocardial segments that have an increased risk of "unintentional perioperative myocardial ischemia."

Limitations. The limitations of this study are related to the following factors.

Contrast agent. Different batches of sonicated albumin may have different concentrations and size distributions, which may significantly affect ultrasonographic reflection. Peak contrast and area under the curve are more affected than contrast wash-in and wash-out parameters. Coulter or laser counting (Coulter Electronics, Hialeah, Fla.), microscopic analysis, and ultrasonic characterization may be used to determine bubble size and concentration; however, these methods are not free from limitations. Microscopic evaluation, although time consuming, is an acceptable method for this purpose and may be used to unequivocally exclude the presence of large bubbles.

Injection technique. Sonicated albumin microbubbles may be unstable under pressure and may collapse or be destroyed during manual injection. In addition, both the speed of contrast injection and infusion of cardioplegic solution may not be constant.

Imaging modality. Myocardial reflectivity may vary with changes in heart position. In addition, at low contrast concentration, myocardial perfusion may be underestimated because of the threshold effect; similarly, at high contrast concentration compression and attenuation of the signal by the commercially available ultrasonographic system may result in perfusion underestimation.

MCE is more sensitive than coronary arteriography in detecting perfusion of the collateralized myocardium $^{5-7}$; thus the assignment of patients to groups with "good" and "poor" collaterals on the basis of coronary angiography may be misleading.

Conclusions. We conclude that intraoperative MCE allows the assessment of myocardial perfusion in the cardioplegia-arrested heart when a complete analysis of all the time-intensity curve variables is done.

Infusion of cardioplegic solution through the aortic root provides adequate myocardial perfusion in the presence of well-developed collateral circulation. Poor collateral circulation is characterized by a high resistance to flow and in this clinical setting coronary angiography may not predict the intraoperative perfusion pattern. In the subset of patients with LAD occlusion and poor collaterals, antegrade cardioplegia may not provide complete myocardial protection, and alternative protective techniques may be used to avoid "unintentional myocardial ischemia," perioperative myocardial necrosis, or myocardial stunning.

\section{REFERENCES}

1. Helfant RH, Vokonas PS, Gorlin R. Functional importance of the human coronary collateral circulation. $\mathrm{N}$ Engl J Med 1971;284:1277-81.

2. Hansen JF. Coronary collateral circulation: clinical significance and influence on survival in patients with coronary artery occlusion. Am Heart J 1989;117:290-5.

3. Berger BC, Watson DD, Taylor GJ, Burwall LR, Martin PP, Beller GA. Effect of coronary collateral circulation on regional myocardial perfusion assessed with quantitative thallium-201 scintigraphy. Am J Cardiol 1980;46:365-70.

4. Keller MW, Spotnitz WD, Matthew TL, Glasheen WP, Watson DD, Kaul S. Intraoperative assessment of regional myocardial perfusion using quantitative myocardial contrast echocardiography: an experimental evaluation. J Am Coll Cardiol 1990;16:1267-79.

5. Reeder GS. Contrast echocardiography and coronary collateral flow. J Am Coll Cardiol 1990;16:1601-2

6. Spotnitz WD, Matthew TL, Keller MW, Powers ER, Kaul S. Intraoperative demonstration of coronary collateral flow using myocardial contrast two-dimensional echocardiography. Am J Cardiol 1990;65:1259-61.

7. Sabia PJ, Powers ER, Ragosta M, Sarembock IJ, Burwell LR, Kaul S. An association between collateral blood flow and myocardial viability in patients with recent myocardial infarction. N Engl J Med 1992;327:1825-31.

8. Caretta Q, Voci P, Bilotta F, et al. Risk factors of incomplete cardioplegia distribution during coronary artery surgery. J Thorac Cardiovasc Surg 1995;109:439-47.

9. Berne RM, Blackman JR, Gardner TH. Hypoxemia and coronary flow. J Clin Invest 1957;36:1101-6.

10. McDonagh PF, Laks $H$. Use of cold blood cardioplegia to protect against coronary microcirculatory injury due to ischemia and reperfusion. J Thorac Cardiovasc Surg 1982;84:609-18.

11. Aronson S, Lee BK, Wiencek JG, et al. Assessment of myocardial perfusion during CABG surgery with two-dimensional transesophageal contrast echocardiography. Anesthesiology 1991;75:433-40.

12. Aronson S, Lee BK, Zaroff JG, et al. Myocardial distribution of cardioplegic solution after retrograde delivery in patients undergoing cardiac surgical procedures. J Thorac Cardiovasc Surg 1993;105:214-21.

13. Kaul S, Kelly P, Oliner JD, Glasheen WP, Keller MW, Watson DD. Assessment of regional myocardial blood flow 
with myocardial contrast two-dimensional echocardiography. J Am Coll Cardiol 1989;13:468-82.

14. Villanueva FS, Spotnitz WD, Jayaweera AR, Dent J, Gimple LW, Kaul S. On-line intraoperative quantitation of regional myocardial perfusion during coronary artery bypass graft operations with myocardial contrast two-dimensional echocardiography. J Thorac Cardiovasc Surg 1992;104:1524-31.

15. Voci P, Bilotta F, Caretta Q, Chiarotti F, Mercanti C, Marino B. Mechanisms of incomplete cardioplegia distribution during coronary artery surgery: an intraoperative transesophageal contrast echocardiography study. Anesthesiology 1993;79:904-12.

16. Kaul S, Glasheen W, Ruddy TD, Pandian NG, Weyman AE, Okada RD. The importance of defining left ventricular area at risk in vivo during acute myocardial infarction: an experimental evaluation with myocardial contrast two-dimensional echocardiography. Circulation 1987;75:1249-60.

17. Caretta Q, Voci P, Bilotta F, Mercanti C, Marino B. Intraoperative detection of coronary artery graft occlusion by myocardial contrast echocardiography. J Cardiothorac Vasc Anesth 1994;8:206-8.

18. Becker H, Vinten-Johansen J, Buckberg GD, Follette DM, Robertson JM. Critical importance of ensuring cardioplegic delivery with coronary stenoses. J Thorac Cardiovasc Surg 1981;81:507-15.

19. Grondin CM, Helias J, Vouhe PR, Robert P. Influence of a critical coronary artery stenosis on myocardial protection through cold potassium cardioplegia. J Thorac Cardiovasc Surg 1981;82:608-15.

20. Buckberg GD. Myocardial management and coronary surgery. J Card Surg 1995;10:68-89.

21. Voci P, Bilotta F, Caretta Q, Mercanti C, Marino B. Lowdose dobutamine echocardiography predicts the early response of dysfunctioning myocardial segments to coronary artery bypass grafting. Am Heart J 1995;129:521-6.

22. Voci P, Bilotta F, Scibilia G, et al. In-vitro development and clinical applications of sonicated echocontrast agents. Am J Card Imaging 1991;5:192-9.

23. Feinstein SB, ten Cate FJ, Zwehl W, et al. Two-dimensional contrast echocardiography: I-in vitro development and quantitative analysis of echo contrast agents. J Am Coll Cardiol 1984;3:14-20.

24. Dixon WJ. BMDP statistical software manual. Berkeley: University of California Press, 1992:155-74;278-81;521-63.

25. Partington MT, Acar C, Buckberg GD, Julia P, Kofsky ER, Bugyi HI. Studies of retrograde cardioplegia: I-capillary blood flow distribution to myocardium supplied by open and occluded arteries. J Thorac Cardiovasc Surg 1989;97:605-12.

26. Schaper J, Konig R, Franz D, Schaper W. The endothelial surface of growing coronary collateral arteries: intimal margination and diapedesis of monocytes: a combined SEM and TEM study. Virchows Arch 1976;370:193-205.

27. Schaper J, Borgers M, Schaper W. Ultrastructure of ischemia-induced changes in the precapillary anastomotic network of the heart. Am J Cardiol 1972;29:851-60.

28. Daggett WM, Jacocks MA, Coleman WS, Johnson RG, Lowenstein E, Vander Salm TJ. Myocardial temperature mapping: improved intraoperative myocardial preservation. $\mathbf{J}$ Thorac Cardiovase Surg 1981;82:883-8.
29. Flameng W, Schwarz F, Hehrlein F. Intraoperative evaluation of the functional significance of coronary collateral vessels in patients with coronary artery disease. Am J Cardiol 1978;42:187-92.

30. Thys DM, Abel M, Bollen BA, et al. Practice guidelines for perioperative transesophageal echocardiography: a report by the American Society of Anesthesiologists and the Society of Cardiovascular Anesthesiologists Task Force on Transesophageal Echocardiography. Anesthesiology 1996; 84:986-1006.

\section{Appendix}

The following notations are used herein:

$\mathrm{x}_{\mathrm{i}}=$ acquisition time $(\mathrm{i}=0,1,2, \ldots, \mathrm{k}, \ldots, 14$, which correspond to $\mathrm{x}_{\mathrm{i}}=0$ second, 0.5 second, 1 second, ..., $\mathrm{k} / 2$ seconds, ..., 7 seconds)

$\overline{\mathrm{x}}=$ mean of $\mathrm{x}_{\mathrm{i}}$ values

$y_{i}=$ background-subtracted intensity value at time $x_{i}$

$\bar{y}=$ mean of $y_{i}$ values

$\mathrm{k}=$ index of the last measure within each time interval ( $\mathrm{k}$ $=2,4, \ldots, 14$ for area at 1 second, area at 2 seconds, ..., area at 7 seconds, respectively)

$\mathrm{k}^{*}=$ index of the time to peak and of the peak height

Peak height and time to peak of the curve were defined as follows:

$$
\text { Peak height }=y^{*}=\max _{i=0}^{14}\left(y_{i}\right)
$$

Time to peak $=\mathrm{x}^{*}=$ acquisition time of the first usable $\mathrm{y}^{*}$ The other parameters of the curve were calculated from the following formulas:

$$
\begin{aligned}
& \text { Areas under the curve }=\sum_{i=0}^{k-1}\left(x_{i+1}-x_{i}\right)\left(y_{i}+y_{i+1}\right) / 2 \\
& \text { Area at peak }=\sum_{i=0}^{k^{* k}-1}\left(x_{i+1}-x_{i}\right)\left(y_{i}+y_{i+1}\right) / 2 \\
& \text { Ascending slope }=\sum_{i=0}^{k^{*}}\left(x_{i}-\bar{x}\right)\left(y_{i}-\bar{y}\right) / \sum_{i=0}^{k^{*}}\left(x_{i}-\bar{x}\right)^{2} \\
& \text { Descending slope }=\sum_{i=k^{*}}^{14}\left(x_{i}-\bar{x}\right)\left(y_{i}-\bar{y}\right) / \sum_{i=k^{*}}^{14}\left(x_{i}-\bar{x}\right)^{2}
\end{aligned}
$$

\footnotetext{
*Peak values.
} 